\title{
GEOMETRICAL MODELLING AND STRUCTURAL ANALYSIS OF THE SARAFIX FIXATOR CONFIGURATIONS
}

\author{
MESIC, E[Imedin]; MUMINOVIC, A[dis] \& REPCIC, N[edzad]
}

\begin{abstract}
This paper presents a structural analysis of Sarafix external fixator configurations, applied to an unstable tibia fracture, using finite element analysis method and experimental testing. The aim was to analyze the interfragmentary displacements at the fracture gap and displacements at the point of load. Structural analyses of Sarafix fixator were performed under three types of loads: axial compression, AP (anterior-posterior) four-point bending and torsion. Verification of the results obtained from a FEA was carried out through experimental testing. A quite good agreement was observed between the results.

Keywords: structural analysis, Finite element analysis, Solid modelling, External fixator
\end{abstract}

\section{INTRODUCTION}

After J.F. Malgaigne invented the external fixator in 1840, their selection and application was generally carried out on empirical grounds and accumulated experience in clinical orthopedics and traumatology [1]. In order to promote and carry out necessary research to improve fixation, a development of a theoretical analysis of problems fixation based on the principles of structural mechanics is pursued.

In the last two decades, a closer link between medical science and other disciplines of science (Technics, Medical Engineering, Biomechanics etc.) has been created, with the aim of multidisciplinary solving contemporary medical problems. One example of association of scientists of different profiles for the purpose of designing and improving medical devices is the application of methods of external fixation and the development of systems for external fixation [4].

External fixator systems are medical devices for stabilization of bone fractures, and their compliance aims at producing an interfragmentary motion that promotes rapid and successful healing. The aim of the fixation technique is anatomical reduction and immobilization of the bone segments, as well as maintenance of this anatomical stabilization concept throughout the treatment by external stiffening of the fracture gap separating the bone segments [2]. This aim is achieved by an external frame that is connected percutaneously to the bone segments by pins or wires. Directions and intensity of interfragmentary displacements have the crucial importance on rapid bone healing [3]. It is possible to control interfragmentary 3D displacements of the fracture gap using FEM model [7]. Optimal mechanical environment, which promotes bone healing, has not been completely defined yet. Both excessively high and excessively low interfragmentary displacements were shown to have adverse effects on bone fracture healing.
Moreover, interfragmentary displacements parallel to the fracture surfaces were shown to result in pseudo-arthrosis instead of fracture healing. Especially, the stability of the fractured bones is required in the initial phase of treatment. On the other hand, after the initial phase of treatment, for the purpose of dynamization process and in order to stimulate consolidation of the bone, it is desirable to control displacements at the fracture gap and coordinate to the trend of fracture healing [3].

Most biomechanical studies of the external fixation analyze only displacement at the point of load of diverse types of fixators and configurations. This paper, except the value of the Sarafix fixator displacements at the point of load, analyzes also displacements at the fracture gap. One of the reasons for determining displacement at the point of load of the external fixators is its impact on the stress generated in the contact of one-half pin-bone. Decreasing the displacements significantly reduces the axial load to the one-half pins, and thus stresses generated at the one-half pin-bone contact. This helps reduce the risk of weakening (relaxation) of the one-half pins and infection in the area around the one-half pin, which is usually related to complications of external fixation of bone [6].

With the aim of determining stability of external fixators, various sensors and transducers are set up on their designs [3]. During the past few years, except of performing the experimental testing, there has been an increased use of solid modelling and FEA, in order to more fully describe the behaviour of the fixator and its components during the loading [7].

This paper presents research results of displacements obtained by structural analysis using CAD/CAE system CATIA (Computer Aided Three-dimensional Interactive Application) and experimental analysis in the case of an unstable tibial fracture. An open fracture at the middle of tibia with fracture gap of $50 \mathrm{~mm}$ (severe extensive injury with a considerable defect of bone structure) was examined. The most complicated aspect of bone fractures, both in terms of complexity of treatment and structural stresses of external fixator, is an open fracture. In the case of open fractures, in the initial phase of treatment, the full load is transferred through the fixator. This paper is part of the overall biomechanical research aimed to determine the influential parameters on the stability of a Sarafix external fixator [5].

Verification of the results obtained from a structural analysis was carried out through experimental testing by comparing values of an appropriate component of displacement at the point of load. 


\section{SARAFIX EXTERNAL FIXATOR}

The idea for the development of the external fixator Sarafix was developed by a group of mechanical engineers and orthopaedists of "prim.dr. Abdulah Nakas" General Hospital, headed by prim.dr. Sukrija Dozic, in Sarajevo under siege, in May 1992. The idea was triggered by the insufficient number of existing fixators, as the result of the expansion of the war activities. Shortly after, the first fixator called Sarajevo war fixator - Sarafix was produced. During the war, the Sarafix found its highest application in the treatment of extensive gunshot-explosive fractures of the extremities. In peacetime traumatology, it is used in accidental injury in traffic accidents and industrial trauma [2].

Sarafix external fixation system represents a unilateral, biplanar external fixator which belongs to a group of modular fixators with half pins [1]. Owing to the high flexibility and mobility, its application is possible to the complete human skeleton. Sarafix is the holder of numerous awards and prizes at international exhibitions of innovations (gold medals at the exhibitions of innovations Brussels Eureka 95 and Geneva 1996).

Before the analysis, two representative configurations of the Sarafix external fixator were selected (configurations B50 and C50). These configurations are the most used configuration of the Sarafix external fixator in the case of an unstable tibial fracture.

Configuration $\mathrm{B}$ is a unilateral external fixator with four half pins placed in proximal and distal segment of bone. All half pins are placed in AP plane, parallel to each other (Fig. 1).

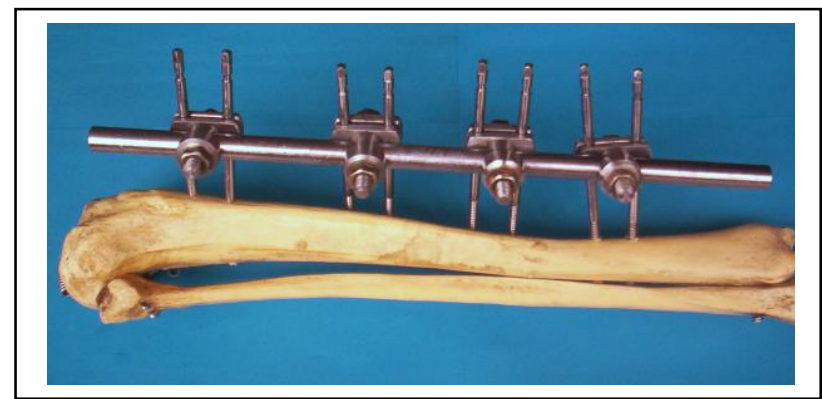

Fig. 1. Configuration B of the Sarafix fixator

Configuration $\mathrm{C}$ is a unilateral, biplanar external fixator with four half pins in proximal and four half pins in distal segment of bone. This configuration has half pins located in two planes and together with other components make up so-called triangular or delta structure, with which we achieve biplane stiffening of bone segments (Fig. 2).

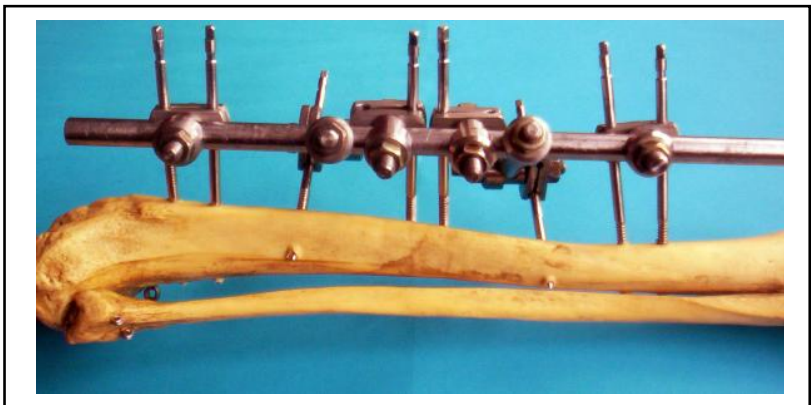

Fig. 2. Configuration C of the Sarafix fixator
Analysed configurations of the Sarafix fixator with value of fracture gap are shown in Tab. 1.

\begin{tabular}{|c|c|c|c|c|}
\hline $\begin{array}{c}\text { Configur } \\
\text { ation }\end{array}$ & Type & $\begin{array}{c}\text { General } \\
\text { mark }\end{array}$ & \multicolumn{2}{|c|}{ Clinical application } \\
\hline B50 & $\begin{array}{c}\text { Unilateral, } \\
\text { uniplanar }\end{array}$ & $4+4$ & \multicolumn{2}{|c|}{$\begin{array}{c}\text { Bones of upper and } \\
\text { lower limbs }\end{array}$} \\
\hline C50 & $\begin{array}{c}\text { Unilateral, } \\
\text { biplanar }\end{array}$ & $4_{\left(45^{\circ}\right)}+4_{\left(45^{\circ}\right)}$ & \multicolumn{2}{|c|}{$\begin{array}{c}\text { Bones of upper and } \\
\text { lower limbs }\end{array}$} \\
\hline $\begin{array}{c}\text { Configur } \\
\text { ation }\end{array}$ & $\begin{array}{c}\text { Number } \text { of } \\
\text { half pins }\end{array}$ & $\begin{array}{c}\text { Number } \\
\text { of } \text { clamps }\end{array}$ & $\begin{array}{c}\text { Number } \\
\text { of clamp } \\
\text { supports }\end{array}$ & $\begin{array}{c}\text { Fracture } \\
\text { gap, mm }\end{array}$ \\
\hline B50 & 8 & 4 & - & 50 \\
\hline C50 & $6+2$ & 6 & 2 & 50 \\
\hline
\end{tabular}

Tab. 1. Analysed configurations of the Sarafix fixator

\section{GEOMETRICAL MODELLING OF THE SARAFIX FIXATOR CONFIGURATIONS}

Geometrical modelling of the Sarafix fixator was carried out at the Laboratory for Computer aided design-CADlab of the Faculty of Mechanical Engineering Sarajevo using CAD/CAE system CATIA [5]. The first step consisted of forming solid models of the Sarafix fixator components: connecting rod, clamp support, modular clamp and half pin (Schanz screw).

In order to form solid models of the Sarafix fixator configurations was necessary to define mutual relations between models of components using constraints of Assembly Design workbench. The following constraints were used (Fig. 3): Contact Constraint, Coincidence Constraint, Offset Constraint and Fix Constraint.

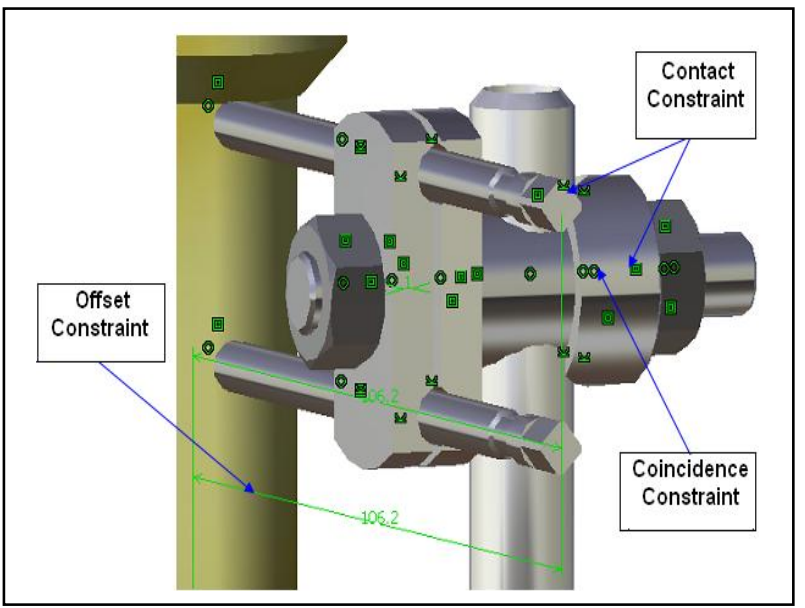

Fig. 3. Defined constraints on Sarafix fixator

Contact Constraint was used to define the contact surfaces between joined parts. The contact surface between two joined geometric elements can be in the form: plane (surface contact), line (line contact), point (point contact) or circle (circle contact). Geometric elements for defining this constraint are: plane, cylinder, sphere, cone and circle. If we use this constraint on two selected surfaces, these surfaces become coplanar. Orientation of coplanar surfaces is determined by their normal vectors. These vectors are turn into opposite directions.

Coincidence Constraint was used to define coincidence between the axis of two joined parts. Depending on the selected geometric elements we can achieve concentricity, coincidence between the axis or 
two element can become coplanar. To define this constraint we can select one of the elements: point, line, plane, curve, surface and axis of coordinate system.

Offset Constraint is used to set the flat surface of two components in a parallel position at a given distance (offset distance). Orientation of these parallel surfaces is determined by the direction of his vectors.

Fix Constraint is used to fix "base" component of the subassembly or assembly in the space to prevent its movement during the model update.

Formed models of Sarafix fixator configurations, dimensionally and geometrically, match the real experimental tested configurations. The open fracture was modelled in the middle of lower leg bone. The distance between central axis of the bone model and fixator connecting rod was $65 \mathrm{~mm}$, which matches the recommended distance from the orthopedic practice in the case of tibia fractures.

Solid models of the B50 and C50 Sarafix fixator configurations are showed at the Fig. 4.

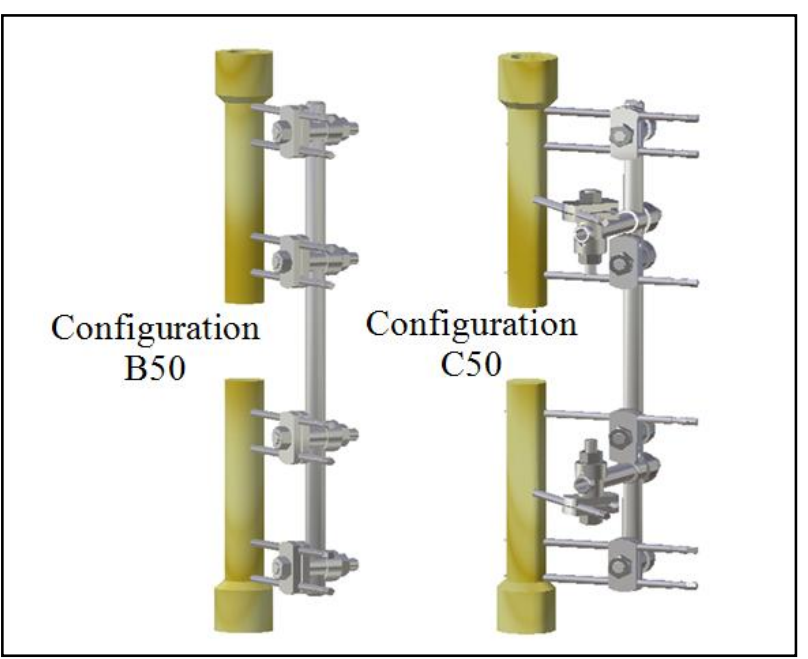

Fig. 4. Solid models of the analyzed configurations Sarafix fixator

After forming 3D model of fixator configurations in the Assembly Design module with above mentioned constraints, the next step is to insert these configurations models in CATIA workbenches for structural analysis Generative and Extended Structural Analysis.

\section{STRUCTURAL ANALYSIS OF THE SARAFIX FIXATOR CONFIGURATIONS}

Understanding the physical behavior of the model is a basic prerequisite for successful process of modelling real systems [8]. Before that, it is necessary to make numerous assumptions related to modelling: structure, joints between the components, boundary conditions, loads, materials, etc.

Structural analysis of the Sarafix fixator configurations was performed on the solid models using CAD/CAE system CATIA [5]. The concept of FEA of fixator Sarafix with activities performed by the preprocessor, solver and postprocessor is shown in Fig. 5.

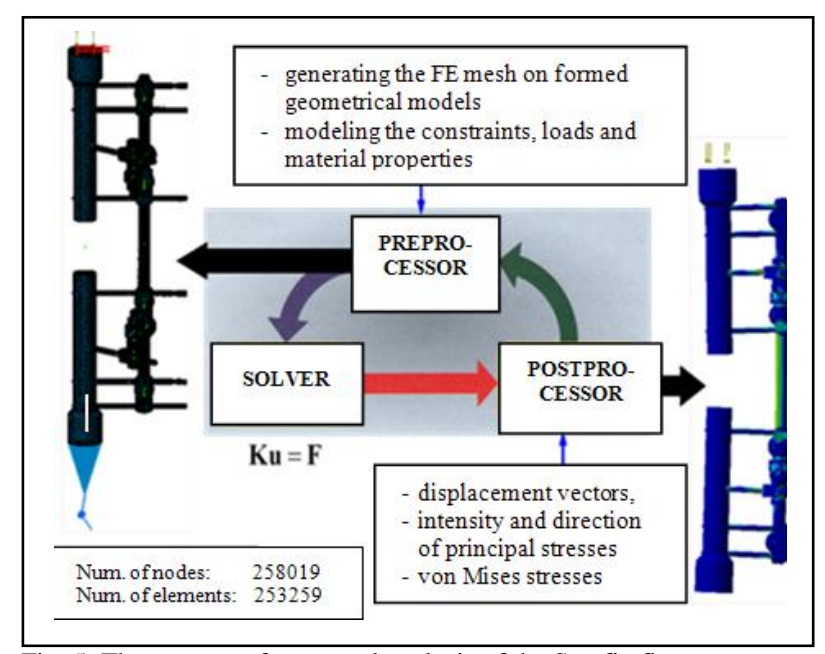

Fig. 5. The concept of structural analysis of the Sarafix fixator

During the processes of FEM modelling and linear structural analysis, material of wooden bone models was defined as orthotropic, while materials of the fixator construction (stainless steels) were modelled as isotropic. Solid elements, types of linear (TE4) and parabolic tetrahedron (TE10) (Fig. 6), were used for modelling structure of Sarafix fixator components.

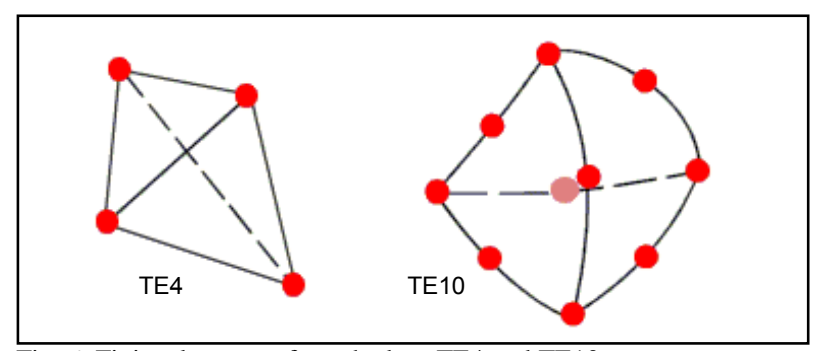

Fig. 6. Finite elements of tetrahedron TE4 and TE10 type

Join elements of the spider type were used for modelling the joints between the components of the Sarafix fixator. The modelling of the influence of supports was performed using a Smooth virtual part. The following joints were used: Fastened connection, Contact connection and Bolt tightening connection. Structural analyses of Sarafix fixator were performed under three types of loads:

- axial compression,

- AP (anterior-posterior) four-point bending and

- torsion.

Absolute displacements of analyzing points at the proximal and distal fracture endplate in the $\mathrm{x}, \mathrm{y}$ and $\mathrm{z}$ direction were determined. Analyzing points were selected in such a manner for the resulting vector of relative displacements $(R)$ has maximal value.

The precise information about displacements at the fracture gap can be provided by analyzing relative displacements of end bone segments under simulated conditions of loads. Relative displacements of the analyzed pairs of points on the endplate of the proximal and distal segments of bone models in $\mathrm{x}, \mathrm{y}$ and $\mathrm{z}$ directions (Fig. 8, 11 and 14) ) are determined as:

$r_{D(x)}=D_{p(x)}-D_{d(x)} ; r_{D(y)}=D_{p(y)}-D_{d(y)} ; r_{D(z)}=D_{p(z)}-D_{d(z)}$

where:

$r_{(D) x}, r_{(D) y}$ and $r_{(D) z}$ - are the relative displacements at the fracture gap in the $\mathrm{x}, \mathrm{y}$ and $\mathrm{z}$ directions $(\mathrm{mm})$, 
$D_{p(x),} D_{p(y)}$ and $D_{p(z)}$ - are the absolute displacements of points at the proximal fracture endplate in the $\mathrm{x}, \mathrm{y}$ and $\mathrm{z}$ direction $(\mathrm{mm})$,

$D_{d(x)}, D_{d(y)}$ and $D_{d(z)}$ - are the absolute displacements of points at the distal fracture endplate in the $\mathrm{x}, \mathrm{y}$ and $\mathrm{z}$ direction $(\mathrm{mm})$.

Based on the values of relative displacements $r_{(D)}$, maximal value of the resulting vector of relative displacements at the fracture gap is determine as:

$$
R=\sqrt{\left(r_{D(x)}\right)^{2}+\left(r_{D(y)}\right)^{2}+\left(r_{D(z)}\right)^{2}}
$$

The analyzed configurations of the Sarafix fixator were attached to proximal and distal tibia bone segment modelled with cylindrical wooden models with the known physical properties. Intensity of load was determined based on in-vivo testing on patients [3].

\subsection{Structural analysis under axial compression}

During the axial compression testing, the bone models were supported on ball joints, while maximal axial loading force applied to the proximal bone model was $F_{p}=600$ N. Fig. 7. shows the 3D FEM model of the analyzed configuration Sarafix fixator before and after the action of maximum axial load.

At the end of the proximal bone segment, the axial load in the form of surface force (Force density) was applied in the direction of the $\mathrm{z}$ axis of the Cartesian coordinate system. A displacement constraint of the Sarafix FEM model was derived by using the Ball join restraint on the model of distal bone segment. Likewise, a displacement constraint at the model of proximal bone segment was performed by using the User-defined restraint, which prevented the two translations in direction of $\mathrm{x}$ and $\mathrm{y}$ axis of the Cartesian coordinate system.

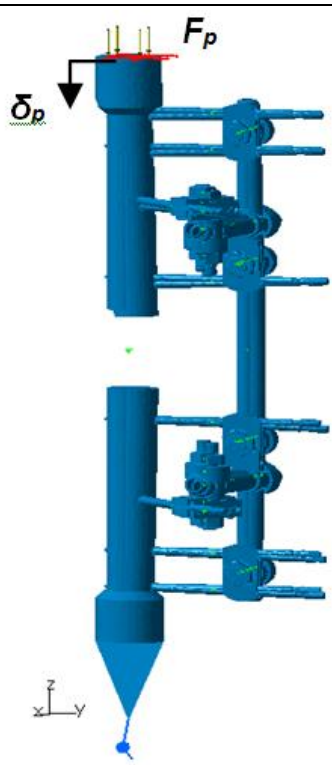

Fig. 7. Non-deformed and deformed structure of the Sarafix fixator configuration C50 under maximum axial load

Values of bone segments displacements at the point of load and fracture gap have been analyzed. Values of displacement of proximal and distal model of the bone segment at the fracture gap under maximal axial load are presented in Tab. 2.

\begin{tabular}{|c|c|c|c|c|c|c|c|c|}
\hline \multirow{3}{*}{ ن் } & \multicolumn{8}{|c|}{ Displacement of the proximal segment, $\mathrm{mm}$} \\
\hline & \multicolumn{4}{|c|}{ Point of load } & \multicolumn{4}{|c|}{ The fracture gap } \\
\hline & $\mathrm{x}$ & $\mathrm{y}$ & \multicolumn{2}{|c|}{\begin{tabular}{|l|}
$\mathrm{Z}$ \\
\end{tabular}} & $D_{p(x)}$ & $D_{p(y)}$ & \multicolumn{2}{|c|}{$D_{p(z)}$} \\
\hline B & 0 & 0 & \multicolumn{2}{|c|}{$-4,01$} & $-0,42$ & 4,05 & \multicolumn{2}{|c|}{$-4,18$} \\
\hline $\mathbf{C}$ & 0 & 0 & \multicolumn{2}{|c|}{$-4,18$} & 0,53 & 4,14 & \multicolumn{2}{|c|}{$-4,36$} \\
\hline \multirow{3}{*}{$\underbrace{5}_{\substack{5 \\
5}}$} & \multicolumn{4}{|c|}{$\begin{array}{l}\text { Displacement of the } \\
\text { distal segment, } \mathrm{mm}\end{array}$} & \multirow{2}{*}{\multicolumn{2}{|c|}{$\begin{array}{l}\text { Max. relat. } \\
\text { displ. at the } \\
\text { gap, mm }\end{array}$}} & \multicolumn{2}{|c|}{$\begin{array}{c}\text { Axial displ. at } \\
\text { the point of } \\
\text { load, } \mathrm{mm}\end{array}$} \\
\hline & \multicolumn{4}{|c|}{ The fracture gap } & & & \multicolumn{2}{|c|}{$\delta_{p}$} \\
\hline & \multicolumn{2}{|c|}{$D_{d(x)}$} & $D_{d(y)}$ & $D_{d(z)}$ & \multicolumn{2}{|c|}{$R$} & FEA & Exp. \\
\hline B & \multicolumn{2}{|c|}{$-0,44$} & 4,2 & 0,25 & \multicolumn{2}{|c|}{4,43} & 4,01 & 4,04 \\
\hline $\mathbf{C}$ & \multicolumn{2}{|c|}{0,53} & 4,29 & 0,22 & \multicolumn{2}{|c|}{4,58} & 4,18 & 4,35 \\
\hline
\end{tabular}

Tab. 2. Values of displacements under maximal axial load

The directions and intensities of displacements at the fracture gap under maximum axial force are observed in the Fig. 8.

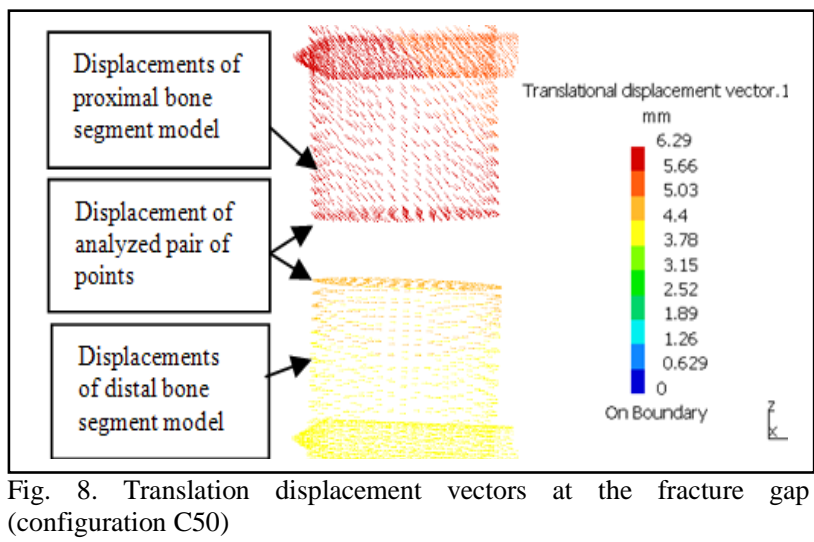

Verification of the results obtained from a FEA was carried out through experimental testing by comparing values of an appropriate component of displacement at the point of load $\left(\delta_{p}\right)$. Diagram of axial displacement proximal segment model of bone at the point of load $\left(\delta_{p}\right)$ was obtained by the structural analysis using FEM and experimental testing (Fig. 9). It shows the intensity of deformation of the analyzed Sarafix fixator configuration during structural analysis under axial compression.

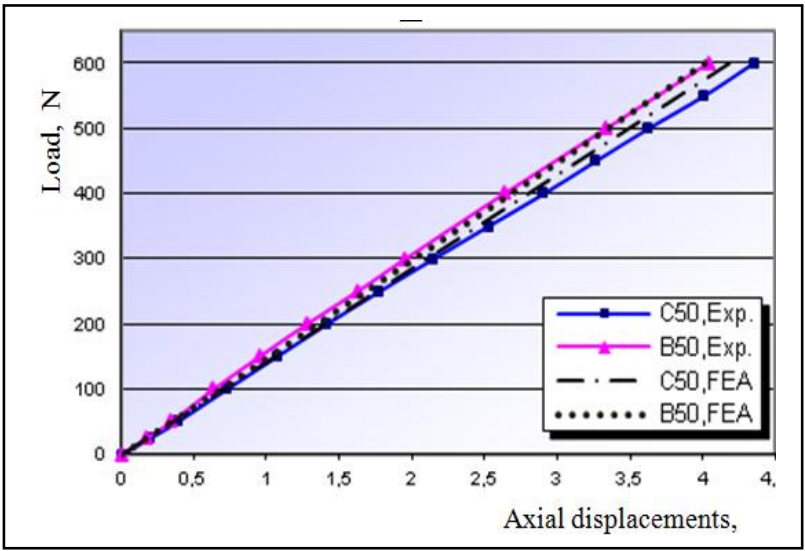

Fig. 9. Comparative diagram of the axial displacement at the point of load

\subsection{Structural analysis under AP bending}

During the testing under AP four-point bending, models of the bones were supported on the cylinders, while the maximum value of bending force was: $F s=$ $500 \mathrm{~N}$. The modelling of the influence of supports was performed using a Contact virtual part. A displacement constraint at the model of proximal and distal bone segment was performed by using the User-defined 
restraint, which prevented the two and three translations in directions of $x, y$ and $z$ axis of the Cartesian coordinate system, respectively (Fig. 10).

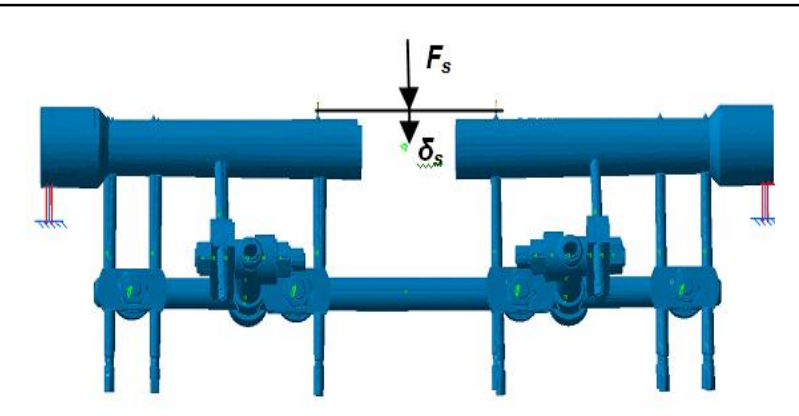

Fig. 10. Non-deformed and deformed structure of the Sarafix fixator configuration $\mathrm{C} 50$ under maximum bending force

Fig. 10 shows the 3D FEM model of the analyzed Sarafix fixator configuration before and after the action of maximum bending force, which acts simultaneously on both models of bone segments.

Values of displacement of proximal and distal model of the bone segment at the fracture gap under maximal AP bending force are presented in Tab. 3 .

\begin{tabular}{|c|c|c|c|c|c|c|c|}
\hline \multirow{3}{*}{ ن் } & \multicolumn{7}{|c|}{ Displacement of the proximal segment, $\mathrm{mm}$} \\
\hline & \multicolumn{3}{|c|}{ Point of load } & \multicolumn{4}{|c|}{ The fracture gap } \\
\hline & $\mathrm{x}$ & $\mathrm{y}$ & $\mathrm{Z}$ & $\mathrm{D}_{\mathrm{p}(\mathrm{x})}$ & $\mathrm{D}_{\mathrm{p}(\mathrm{y})}$ & \multicolumn{2}{|c|}{$\mathrm{D}_{\mathrm{p}(\mathrm{z})}$} \\
\hline $\mathbf{B}$ & 0,13 & 2,47 & $-0,57$ & 0,15 & 2,81 & \multicolumn{2}{|c|}{$-0,53$} \\
\hline $\mathbf{C}$ & 0,07 & 2,48 & $-0,57$ & $-0,03$ & 2,8 & \multicolumn{2}{|c|}{$-0,53$} \\
\hline 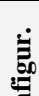 & \multicolumn{3}{|c|}{$\begin{array}{l}\text { Displacement of the } \\
\text { distal segment, } \mathrm{mm}\end{array}$} & \multirow{2}{*}{\multicolumn{2}{|c|}{$\begin{array}{l}\text { Max. relat. } \\
\text { displ. at the } \\
\text { gap, mm }\end{array}$}} & \multicolumn{2}{|c|}{$\begin{array}{c}\text { Deflection at } \\
\text { the point of } \\
\text { load, } \mathrm{mm}\end{array}$} \\
\hline فَّ & \multicolumn{3}{|c|}{ The fracture gap } & & & \multicolumn{2}{|c|}{$\boldsymbol{\delta}_{\mathrm{s}}$} \\
\hline & $\mathrm{D}_{\mathrm{d}(\mathrm{x})}$ & $\mathrm{D}_{\mathrm{d}(\mathrm{y})}$ & $\mathrm{D}_{\mathrm{d}(\mathrm{z})}$ & \multicolumn{2}{|c|}{$\mathrm{R}$} & FEA & Exp. \\
\hline B & 0,15 & 2,81 & 2,09 & \multicolumn{2}{|c|}{2,62} & 2,47 & 2,60 \\
\hline $\mathbf{C}$ & $-0,03$ & 2,8 & 2,21 & \multicolumn{2}{|c|}{2,74} & 2,48 & 2,59 \\
\hline
\end{tabular}

Tab. 3. Values of displacements under maximal AP bending force

The directions and intensities of displacements at the fracture gap under maximum bending force are observed in the Fig. 11.

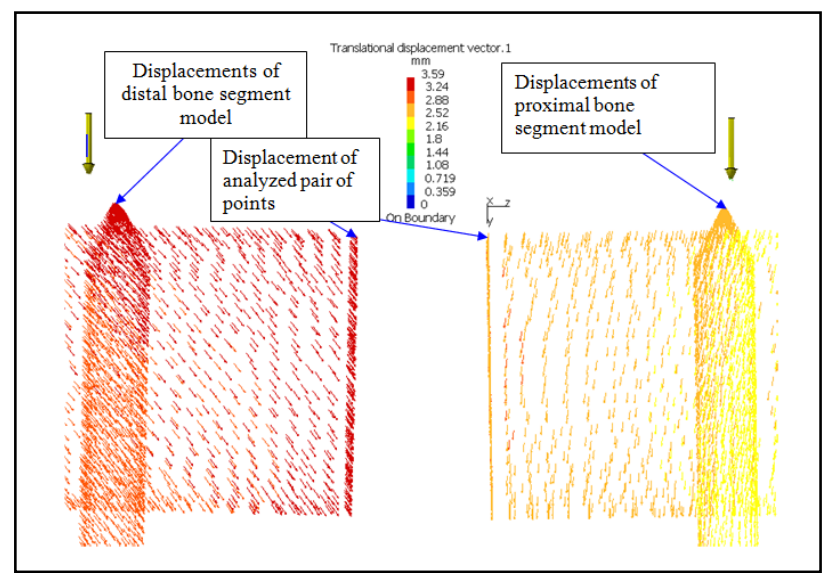

Fig. 11. Translation displacement vectors at the fracture gap under maximum bending force (configuration $\mathrm{C} 50$ )

Verification of the results obtained from a FEA was carried out through experimental testing by comparing values of deflection at the point of load $\left(\delta_{s}\right)$. Diagram of the displacement proximal and distal segments of the bone models at the point of load was obtained by structural analysis using FEA and experimental testing (Fig. 12)

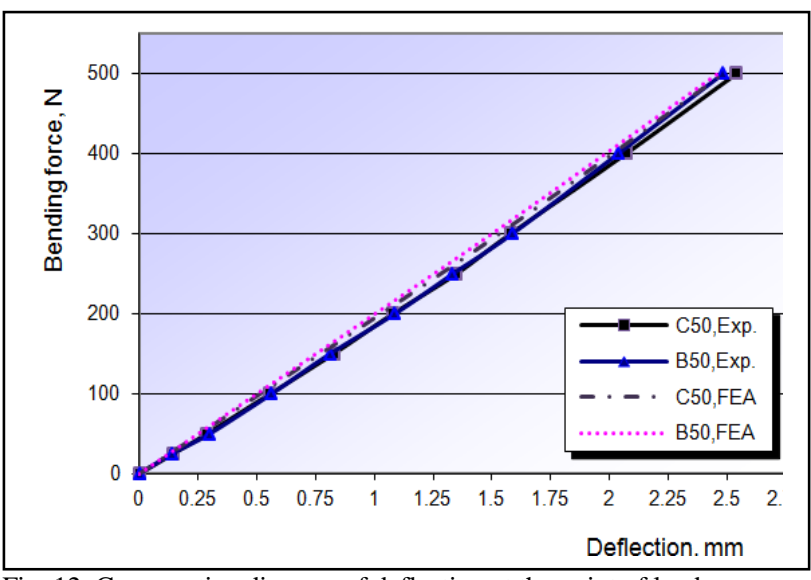

Fig. 12. Comparative diagram of deflection at the point of load

\subsection{Structural analysis under torsion}

Testing under torsion was carried out by the principle of rotation distal segment of the bone model in relation to the fixed proximal segment (Fig. 13). At the end of the distal segment of bone model, in the appropriate place we put constraint in the form of a cylindrical joint.

Torsion moment is defined on the hole surface in the distal segment of bone model. The maximum value of the torque was: $M_{u}=15 \mathrm{Nm}$

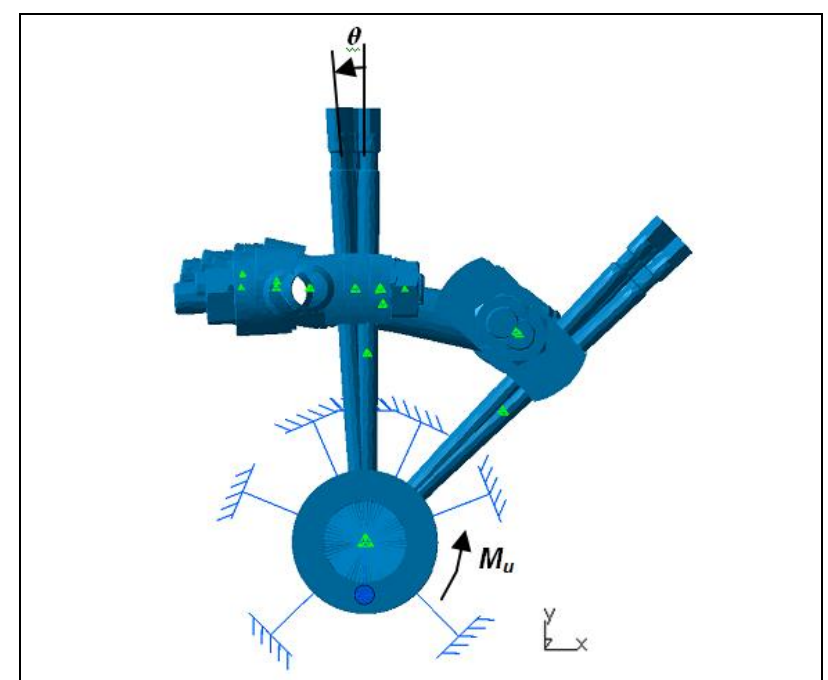

Fig. 13. Non-deformed and deformed structure of the Sarafix fixator configuration C50 under maximum torque

Values of displacement of proximal and distal model of the bone segment at the fracture gap and at the point of load under maximum torque are presented in Tab. 4.

\begin{tabular}{|c|c|c|c|c|c|c|c|}
\hline \multirow{3}{*}{ ن் } & \multicolumn{7}{|c|}{ Displacement of the proximal segment, $\mathrm{mm}$} \\
\hline & \multicolumn{3}{|c|}{ Point of load } & \multicolumn{4}{|c|}{ The fracture gap } \\
\hline & $\mathrm{x}$ & $\mathrm{y}$ & $\mathrm{Z}$ & $\mathrm{D}_{\mathrm{p}(\mathrm{x})}$ & $\mathrm{D}_{\mathrm{p}(\mathrm{y})}$ & \multicolumn{2}{|c|}{$\mathrm{D}_{\mathrm{p}(\mathrm{z})}$} \\
\hline B & 1,66 & 0,33 & 0 & 1,18 & 0,01 & \multicolumn{2}{|c|}{0} \\
\hline $\mathbf{C}$ & 1,23 & 0,33 & 0 & 0,82 & 0 & \\
\hline \multirow{3}{*}{$\dot{\Xi}$} & \multicolumn{3}{|c|}{$\begin{array}{l}\text { Displacement of the } \\
\text { distal segment, } \mathrm{mm}\end{array}$} & \multirow{2}{*}{\multicolumn{2}{|c|}{$\begin{array}{l}\text { Max. relat. } \\
\text { displ. at the } \\
\text { gap, mm }\end{array}$}} & \multicolumn{2}{|c|}{$\begin{array}{c}\text { Torsion angle } \\
\text { at the point of } \\
\text { load }\end{array}$} \\
\hline & \multicolumn{3}{|c|}{ The fracture gap } & & & \multicolumn{2}{|c|}{$\theta$, degree } \\
\hline & $\mathrm{D}_{\mathrm{d}(\mathrm{x})}$ & $\mathrm{D}_{\mathrm{d}(\mathrm{y})}$ & $\mathrm{D}_{\mathrm{d}(\mathrm{z})}$ & & FEA & Exp. \\
\hline $\mathbf{B}$ & $-0,04$ & $-0,02$ & 0 & \multicolumn{2}{|c|}{1,22} & 5,61 & 5,88 \\
\hline $\mathbf{C}$ & 0,05 & 0 & 0 & \multicolumn{2}{|c|}{0,76} & 4,16 & 4,36 \\
\hline
\end{tabular}

Tab. 4. Values of displacements under maximum torque 
The directions and intensities of displacements at the fracture gap under maximum torque are observed in the Fig. 14.

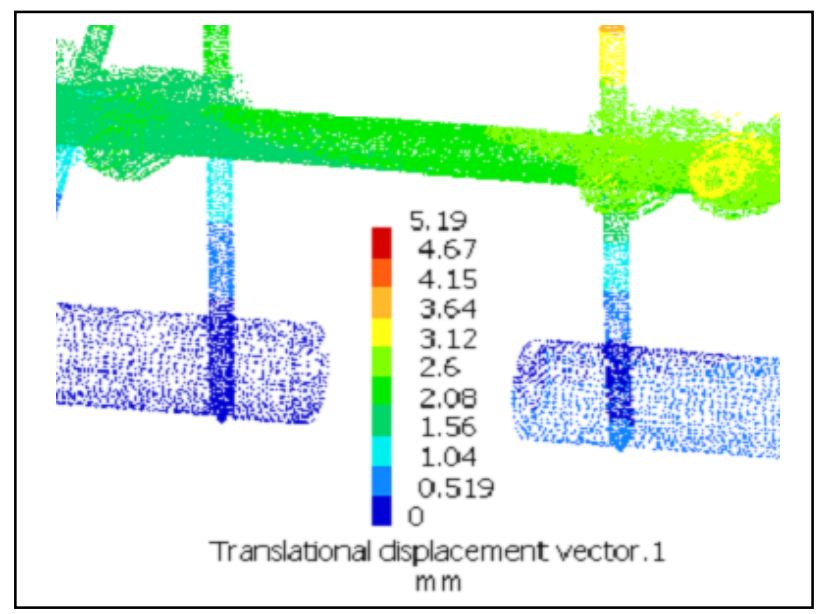

Fig. 14. Translation displacement vectors at the fracture gap under maximum torque (configuration $\mathrm{C} 50$ )

Using structural analysis and experimental testing a diagram of torsion angle of proximal segment model of bone at the point of load was obtained (Fig. 15), which also shows the intensity of deformation of the Sarafix fixator configuration during testing under torsion.

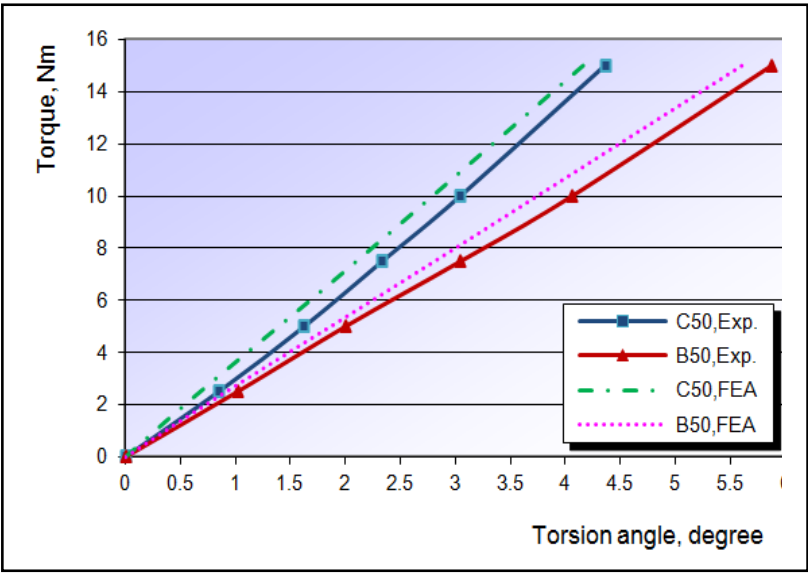

Fig. 15. Comparative diagram of torsion angle at the point of load

\section{CONCLUSION}

The conducted research has shown that there is a linear dependence between the load and displacement of the bone segments, as a result of the absence of large rotation, displacement and plastic deformation of the fixator components. The above fact is also a basic requirement for the fixator's stability in terms of preserving anatomical reduction of bone fragments in the postoperative load conditions. Detailed data of the stability of external fixation systems are needed by the orthopedic surgeon to predict successful healing of a fracture.

By displacing a half pins on both an proximal and distal segment of the bone model into a plane closing a 45 degrees angle to AP plane and their placing closer to areas of a bigger bone cross cut (configuration $\mathrm{C}$ ), axial displacement and deflection are approximately the same, while torsion angle has been significantly decreased
(Tab. 4 and Fig. 15). Configuration $\mathrm{C}$ is more suited to the anatomy of the tibia and this configuration can handle higher loads (especially torque).

From the diagrams can be seen a good mach of results obtained by FEA and experimental analysis. In this way, we can conclude that the solutions obtained by FEA were verified, i.e. the developed FEM model of the Sarafix fixator was verified. Using the developed FEM model of the Sarafix fixator, it is possible to track 3D displacement of any point of the bone-fixator system and interfragmentary displacements within the area of fracture.

It is shown that the CAD/CAE system CATIA can be successfully used in the development of geometrical models, FEM analysis and computer simulations of the process from different areas of techniques and medicine. In addition, the application of such models greatly reduces the volume of conventional preclinical experimental testing of fixators.

Plans for further work are:

- research the influence of other structural and geometrical parameters on the stability of the fixator,

- creating more realistic geometric and FEM models of bone segments using 3D scanning technique, computer tomography or magnetic resonance imaging,

- perform in-vivo test and

- make improvements on fixator construction using design optimization.

The next study will focus on the forming of CAD system for structural optimization of external fixators.

\section{REFERENCES}

[1] Behrens, F. (1989). General Theory and Principles of External Fixation. Clin Orthop, Vol. 241, Num.5, 1989, pp. 15-23

[2] Dozic, S. (2011). Biomehaničke karakteristike unilateralnog, biplanarnog Sarajevskog ratnog fiksatora "Sarafix" u liječenju strijelno-eksplozivnih akcidentalnih prijeloma dugih kostiju ekstremiteta, Ph.D. Dissertation, Faculty of Medicine, University of Sarajevo, Sarajevo, B\&H

[3] Jasinska-Choromanska, D. \& Sadzynski, I. (2001). Monitoring Technique of Bone Fracture Healing Using External Fixators, 39th International Conference, Experimental Stress Analysis, Czech Republic, 2001, pp. 35-40

[4] Mesic, E.; Muminovic, A; \& Repcic, N. (2012). Mechanical Stability Analysis of the External Fixation System Sarafix Proceedings of the $12^{\text {th }}$ International Design Conference DESIGN 2012, Session D435: Life science and design for healthcare, ed: Marjanović D., May 21-24, Dubrovnik, Croatia, 2012, pp.1029-1038, ISSN 1848-4700

[5] Mesic, E. (2008). Istraživanje mehaničke stabilnosti sistema za spoljašnju fiksaciju Sarafix, M.Sc. thesis, Faculty of Mechanical Engineering, University of Sarajevo, Sarajevo, B\&H

[6] Oh, J.K.; Lee, J.J.; Jung, D.K.; Kim, B.J. \& Oh, C.W. (2004) Hybrid External Fixation of Distal Tibial Fractures: New Strategy to Place Pins and Wires without Penetrating The Anterior Compartment, Arch Orthop Trauma Surg, 124, SpringerVerlag, pp. 542-546

[7] Radke, H.; Aron, D.N.; Applewhite, A. \& Zhang, G. (2006). Biomechanical Analysis of Unilateral External Skeletal Fixators Combined with IM-Pin and without IM-Pin Using Finite-Element Method, Veterinary Surgery (35), 2006, pp. 15-23

[8] Zienkiewicz, O.C. \& Taylor, R.L. (2003). The Finite Element Method - Volume 2: Solid Mechanics. 5th ed., ButterworthHeinemann, Oxford 